\title{
THE CLINICAL SIGNIFICANCE OF A POSITIVE AMNISURE TESTTM IN WOMEN WITH TERM LABOR WITH INTACT MEMBRANES
}

\author{
Seung Mi LEE, MD ${ }^{1}$, JoonHo LEE, MD ${ }^{1}$, Hyo Suk SEONG, MD ${ }^{1}$, Si Eun LEE, MD ${ }^{1}$, Joong Shin \\ PARK, MD, PhD ${ }^{1}$, Roberto ROMERO, MD², and Bo Hyun YOON, MD, PhD ${ }^{1}$ \\ ${ }^{1}$ Department of Obstetrics and Gynecology, Seoul National University College of Medicine, Seoul, \\ Korea \\ ${ }^{2}$ Perinatology Research Branch, NICHD/NIH/DHHS, Bethesda, MD, and Detroit, MI
}

\section{Abstract}

Objective-The Amnisure ROM ${ }^{\mathrm{TM}}$ test is approved for the diagnosis of rupture of membranes (ROM). Yet, a fraction of patients with a positive test have intact membranes by sterile speculum examination. The objective of this study was to determine the clinical significance of this finding.

Methods-The study population consisted of 4 groups of nulliparous women at term: 1) not in labor without clinical evidence of ROM $(n=125) ; 2)$ in labor without clinical ROM with a negative Amnisure test $\left.\mathrm{T}^{\mathrm{TM}}(\mathrm{n}=56) ; 3\right)$ in labor without clinical ROM with a positive Amnisure test $\mathrm{t}^{\mathrm{TM}}(\mathrm{n}=25)$; and 4) in labor with clinical ROM ( $\mathrm{n}=30)$. The Amnisure test ${ }^{\mathrm{TM}}$ was performed in cases without clinical ROM (Groups 1, 2 and 3).

Results-1) The Amnisure test ${ }^{\mathrm{TM}}$ was positive more frequently in women in labor with intact membranes than in patients not in labor at term without ROM (30.9\% (25/81 women) vs. 4.8\% (6/125 women); $\mathrm{p}<0.001)$; 2) patients in labor without clinical ROM with a positive Amnisure test ${ }^{\mathrm{TM}}$ had a significantly shorter admission-to-delivery interval than those in labor without clinical ROM with a negative Amnisure test ${ }^{\mathrm{TM}}(\mathrm{p}<0.05)$.

Conclusion-1) A positive Amnisure test ${ }^{\mathrm{TM}}$ is present in about one-third nulliparous women at term presenting in labor with intact membranes; 2) Patients with a positive Amnisure test ${ }^{\mathrm{TM}}$ had a shorter admission-to-delivery interval than those with a negative test.

\section{Keywords}

Amnisure ROM test ${ }^{\mathrm{TM}}$; placental alpha microglobulin-1; rupture of membranes; labor; term birth

\section{Introduction}

The Amnisure ROM test ${ }^{\mathrm{TM}}$ is a new method to diagnose rupture of the fetal membranes (ROM). The test detects placental alpha-microglobulin-1 (PAMG-1) in cervicovaginal fluid. The concentration of this protein in amniotic fluid is 1,000-10,000 times higher than in the case of cervicovaginal fluid $(2,000-25,000 \mathrm{ng} / \mathrm{mL}$ versus $0.05-2.0 \mathrm{ng} / \mathrm{mL}) .{ }^{1-3}$ Therefore, the presence of high concentrations of PAMG-1 in cervicovaginal fluid is considered evidence of ROM, and the threshold of the test for the diagnosis of ROM has been set at $5.0 \mathrm{ng} / \mathrm{mL}$.

Correspondence to: Bo Hyun Yoon, MD, PhD, Department of Obstetrics and Gynecology, Seoul National University College of Medicine, Seoul, 110-744, Korea. Tel: 82-2-2072-2826, Fax: 82-2-765-3002, E-mail: Yoonbh@ snu.ac.kr. 
Clinical experience with this test indicates the existence of a subgroup of patients with a positive Amnisure test ${ }^{\mathrm{TM}}$ without evidence of ROM by standard criteria (including pooling, nitrazine, and ferning). ${ }^{4}$ A positive Amnisure test ${ }^{\mathrm{TM}}$ without clinical evidence of ROM has been considered as a false positive test, and the precise clinical significance of this finding has not yet been determined.

Some investigators have proposed that high concentrations of PAMG-1 in cervicovaginal fluid in patients without clinical proof of ROM may represent evidence of microleakage of amniotic fluid. ${ }^{4}$ The objective of our study was to determine the frequency of a positive Amnisure test ${ }^{\mathrm{TM}}$ in term pregnant women without clinical evidence of ROM, as well as the outcome of such patients.

\section{Methods}

\section{Study population}

Term nulliparous women with singleton pregnancies admitted to the Seoul National University Hospital were asked to participate in a prospective cohort study designed to examine the clinical significance of a positive Amnisure ROM test ${ }^{\mathrm{TM}}$ in cases with intact membranes. Cases with premature rupture of membranes were not included. A total of 236 women agreed to participate in the study. The Institutional Review Board of Seoul National University Hospital approved this study, and written informed consent was obtained from all patients for the collection and analysis of specimens and clinical data. Patients were divided into 4 groups according to the presence or absence of labor, clinical evidence of ROM, and the result of Amnisure ROM test $^{\mathrm{TM}}$ : Group 1-without labor or clinical evidence of ROM (admitted for elective Cesarean section or induction of labor) ( $\mathrm{n}=125)$; Group 2-labor without clinical evidence of ROM with a negative Amnisure ROM test ${ }^{\mathrm{TM}}(\mathrm{n}=56)$; Group 3-labor without clinical evidence of ROM with a positive Amnisure ROM test ${ }^{\mathrm{TM}}(\mathrm{n}=25)$; and Group 4-labor with clinical evidence of ROM $(\mathrm{n}=30)$ (Figure 1). The Amnisure ROM test ${ }^{\mathrm{TM}}$ was performed in cases without clinical evidence of ROM (Groups 1, 2, and 3).

\section{Diagnosis of clinical ROM}

"Clinical ROM" was diagnosed: 1) if the leakage of amniotic fluid from the cervical os was seen on speculum examination, or 2) if two of the following three signs were present: pooling of amniotic fluid in the vaginal fornix, a positive nitrazine test, and a positive ferning test.

Women who had neither history nor clinical evidence of ROM were considered as those without clinical ROM. Four cases in which a history and clinical evidence showed discrepancy were excluded.

\section{Performance of Amnisure ROM test ${ }^{\mathrm{TM}}$}

The Amnisure ROM test ${ }^{\mathrm{TM}}$ (placental alpha-microglobulin-1 immunoassay, Amnisure ROM test, N-Dia Inc, New York, NY) was performed in patients without clinical ROM (groups 1-3), according to manufacturer's instructions. Briefly, a sterile polyester swab provided by the manufacturer was inserted into the vaginal fornix for 1 minute. The swab was placed into the solvent and rinsed for 1 minute. After removing the swab, the test strip was dipped into the solvent, and the result was determined after 5-10 minutes. This immunoassay result was reported as positive or negative.

\section{Statistical analysis}

Proportions were compared with the Fisher's exact test. Kruskal-Wallis analysis of variance test was utilized for comparison of continuous variables among groups. Multiple comparisons of continuous variables between groups were performed with the Mann-Whitney $U$ test. The 
generalized Wilcoxon test for survival analysis was used to compare the admission-to-delivery interval. Patients who underwent Cesarean delivery during labor had their admission-toCesarean section interval treated as censored observations, with a censoring time equal to the admission-to-delivery interval. Cox proportional hazards modeling was used to compare the admission-to-delivery interval between groups after adjustment for confounding variables. A probability value of $<0.05$ was considered significant.

\section{Results}

\section{Result of Amnisure ROM test ${ }^{\mathrm{TM}}$}

The Amnisure ROM test ${ }^{\mathrm{TM}}$ was performed in 206 patients without evidence of clinical ROM (Groups 1,2 and 3), and was positive in $4.8 \%$ of patients without labor (6/125 in group 1) and in $30.9 \%$ (25/81 in groups 2 and 3) of patients in labor without clinical ROM. ROM was identified by the leakage of amniotic fluid during the subsequent course of labor in all cases with labor, but without clinical evidence of ROM at admission (groups 2 and 3).

\section{Characteristics of the study population}

Table 1 shows the demographic characteristics of the study population. There were no significant differences in maternal age, BMI, gestational age, cervical dilatation and birth weight among three groups of cases with labor at admission (groups 2, 3 and 4).

\section{Pregnancy outcomes}

Figure 2 describes the admission-to-delivery interval among 3 groups (Groups 2, 3 and 4). In 8 patients who were delivered by cesarean section, this interval was censored. The indications for cesarean section were failure to progress in all 8 cases. Patients in labor without clinical ROM, with a positive Amnisure test ${ }^{\mathrm{TM}}$ (Group 3), had a significantly shorter admission-todelivery interval than patients in labor without clinical ROM with a negative Amnisure ROM test $^{\mathrm{TM}}$ (Group 2) (median $6.88 \mathrm{hrs,} \mathrm{range} 1.18$ - $15.98 \mathrm{hrs}$ in Group 3 versus median $9.79 \mathrm{hrs,}$ range 2.32 - $33.07 \mathrm{hrs}$ in Group 2; $\mathrm{p}<0.05$ ). However, there was no significant difference in the admission-to-delivery interval between patients without clinical ROM but with a positive Amnisure test ${ }^{\mathrm{TM}}$ (Group 3), and those with clinical ROM (Group 4) (p>0.1, see figure 2).

Multivariate survival analysis demonstrated that the admission-to-delivery interval in patients without clinical ROM but with a positive Amnisure test ${ }^{\mathrm{TM}}$ was shorter than that of patients without clinical ROM and with a negative Amnisure ROM test ${ }^{\mathrm{TM}}$, after adjusting for confounding variables such as maternal age, maternal pre-pregnancy BMI, length of gestation, cervical effacement and dilatation at admission, birthweight, the use of oxytocin augmentation, and the use of regional analgesia.

\section{Discussion}

\section{Principal findings of the study}

1) The Amnisure ROM Test ${ }^{\mathrm{TM}}$ was positive in $31 \%$ of term nulliparous women presenting with labor with clinically intact membranes and in 5\% of those without labor; 2) A positive Amnisure Test $^{\mathrm{TM}}$ was associated with a shorter admission-to-delivery interval.

\section{Clinical and biological background}

A conclusive diagnosis of ROM can be made when leakage of amniotic fluid from the cervical os is observed at the time of speculum examination. Sometimes, the diagnosis can be difficult to make in some patients, and standard practice consists of using a combination of pooling of amniotic fluid, a nitrazine test and a ferning test. However, a nitrazine test can give a false positive result if the sample is contaminated with blood, semen or antiseptics, or if the patient 
has vaginitis or cervicitis. ${ }^{5,6}$ On the other hand, false negative results can be obtained when the amount of fluid available for analysis is scant. ${ }^{5}$ Ferning suggests amniotic fluid rather than cervical fluid in pregnancy, but this test can also yield incorrect results in the case of the presence of fingerprints on a slide, semen, cervical mucus or blood contamination, or a dry swab. ${ }^{7-9}$

Several alternative tests-including alpha-fetoprotein ${ }^{10}$, insulin-like growth factor binding protein- $1^{11,12}$, fetal fibronectin, ${ }^{13}$ and prolactin ${ }^{14,15}$ have been suggested for the diagnosis of ROM. However, tests based on these analytes have not produced a satisfactory diagnostic performance.

The Amnisure ROM test ${ }^{\mathrm{TM}}$ is an immunoassay that detects high concentrations of PAMG-1 present in amniotic fluid. PAMG-1 is present in very low concentrations in blood or in cervicovaginal fluid when the membranes are intact.

\section{Strength and weakness of the study}

Several studies have shown an excellent accuracy of the Amnisure test ${ }^{\mathrm{TM}}$ in the diagnosis of ROM. Cousin et al. reported a sensitivity of $98.0 \%$, specificity of $100 \%$, positive predictive value of $100 \%$, and a negative predictive value of $99.1 \%$ in a population with a ROM prevalence of $44.8 \%{ }^{3}$ Lee et al. demonstrated that the Amnisure test ${ }^{\mathrm{TM}}$ has a better diagnostic accuracy than the nitrazine test, even when conventional clinical criteria were used (a combination of pooling, nitrazine and ferning). ${ }^{4}$

In light of the high diagnostic accuracy of the Amnisure test ${ }^{\mathrm{TM}}$, the clinical significance of a positive Amnisure test ${ }^{\mathrm{TM}}$ without clinical evidence of ROM needs to be determined. We have proposed that this discrepancy could be attributed to "microscopic ROM" and leakage of amniotic fluid detected as a positive Amnisure test ${ }^{\mathrm{TM}}$. To our knowledge, ours is the first study to examine the outcome of patients with discrepant clinical tests and findings. We found that the prevalence of discrepant tests is higher in women in labor than in women not in labor.

Moreover, we established that patients in labor, with discrepant results, had a shorter intervalto-delivery than those with a negative Amnisure test ${ }^{\mathrm{TM}}$ and intact membranes.

\section{Microscopic ROM in other studies}

A discrepancy between the results of an Amnisure test ${ }^{\mathrm{TM}}$ and sterile speculum examination was also reported in the study of Lee et al. ${ }^{4}$ Among this study's 184 patients who were admitted with signs or symptoms of ROM, 23 showed a positive Amnisure test ${ }^{\mathrm{TM}}$ in spite of a negative sterile speculum examination for ROM. Among these 23 individuals, 10 had labor at presentation (6 patients at term and 4 patients with preterm gestations) and 20 patients were subsequently diagnosed as ROM by repeated examinations performed later during admission. Of major interest is that all patients with preterm labor and intact membranes who had a positive Amnisure test ${ }^{\mathrm{TM}}$ delivered within 7 days.

Erdemoglu et al. examined the PROM test (detection of IGF BP-1 in cervicovaginal secretions) in patients with a history of PROM, but with a negative sterile speculum examination. ${ }^{11}$ In these patients, a positive result of the PROM test was the only predictor of delivery within 7 days. A positive PROM test was also interpreted as reflecting "microscopic ROM."

Our study included only term pregnant women, and examined the prevalence of a positive Amnisure test ${ }^{\mathrm{TM}}$ in patients without a history and clinical evidence of ROM. The prevalence of a positive Amnisure test ${ }^{\mathrm{TM}}$ with a negative sterile speculum examination in women in labor at term was $30.9 \%$. Clearly, this is higher than the prevalence of ROM at term, which is $10 \%$. 


\section{Clinical significance}

Our finding that patients with labor and a positive Amnisure test ${ }^{\mathrm{TM}}$ or clinical ROM had a shorter duration of labor than those without clinical ROM and a negative Amnisure test ${ }^{\mathrm{TM}}$ is consistent with the results of Gross et al., who found that labor was much shorter if patients had ROM at admission, although they did not consider the presence of labor at presentation. 16

\section{Unanswered questions and proposal for future research}

What is the cause of a positive Amnisure test ${ }^{\mathrm{TM}}$ in patients without clinical evidence of ROM? The different prevalence of a positive Amnisure test ${ }^{\mathrm{TM}}$ between the group without labor (Group 1) and the groups in labor without clinical ROM (Groups 2 and 3) do not seem to originate from a difference in gestational age, because mean gestational age at admission of Group 1 (no labor) was not significantly different with that of laboring groups (Groups 2 and 3), while the prevalence of a positive Amnisure test ${ }^{\mathrm{TM}}$ did not increase with gestational age $(\mathrm{p}>0.1)$. In addition, the prevalence of a positive Amnisure test ${ }^{\mathrm{TM}}$ was not increased with cervical effacement or dilatation in patients with labor and intact membranes (Groups 2 and 3; $>>0.1$ ). This finding suggests that a positive Amnisure test ${ }^{\mathrm{TM}}$ may be associated with labor itself, rather than increased gestational age or cervical dilatation. One possible mechanism of a positive Amnisure test ${ }^{\mathrm{TM}}$ in patients without clinical evidence of ROM is that labor may cause microperforations in fetal membranes, through which only a small amount of amniotic fluid can pass. Another possible mechanism is that labor may induce increased intrauterine pressure, which could result in increased transudation of amniotic fluid through the chorioamniotic membranes. Maan et al. showed that chorioamniotic membrane pores of ovine fetuses allowed transmembranous passage of non-polar solutes of up to $69 \mathrm{kd}$ molecular weight, which is bigger than $34 \mathrm{kd}$ molecular weight of PAMG- $1 .{ }^{17}$ Through this pre-existing membrane porosity, PAMG-1 can transudate with increased intrauterine pressure. Unlike conventional clinical tests, the high sensitivity of an Amnisure test ${ }^{\mathrm{TM}}$ may make it possible to detect a very small amount of PAMG-1 in cervicovaginal fluid which passed chorioamniotic membranes during labor.

The clinical meaning of a positive Amnisure test ${ }^{\mathrm{TM}}$ with a negative sterile speculum examination needs to be determined in patients with preterm labor, since the studies of Erdemoglu et al. ${ }^{11}$ and Lee et al. ${ }^{4}$ suggest that microscopic ROM could be associated with delivery within 7 days. Moreover, the determination of whether a positive Amnisure test ${ }^{\mathrm{TM}}$ can detect preterm PROM in its preclinical phase is critical. The relationship between a positive Amnisure test ${ }^{\mathrm{TM}}$ and intra-amniotic infection and/or inflammation also needs to be determined, because labor itself is associated with intra-amniotic infection and/or inflammation, histologic chorioamnionitis and acute inflammation gene expression signature in term pregnant women. $18-20$

In conclusion, a positive Amnisure test $\mathrm{TM}^{\mathrm{TM}}$ is present in about one-third of term laboring nulliparas who subsequently have a shorter interval-to-delivery than women with a negative test.

\section{Acknowledgement}

This research was supported in part by the Intramural Research Program of the Eunice Kennedy Shriver National Institute of Child Health and Human Development, NIH, DHHS.

The Amnisure ROM test TM (the placental alpha-microglobulin-1 immunoassay) kits were provided free of charge by the Korean supplier of N-Dia Inc (New York, NY). N-Dia Inc did not contribute funds toward this study. None of the authors own any stock in this company and are either current or former employees of this company or are members of a speaker's bureau for this company. 


\section{References}

1. Petrunin DD, Griaznova IM, Petrunina IuA, Tatarinov IuS. Immunochemical identification of organ specific human placental alphal-globulin and its concentration in amniotic fluid. Akush Ginekol 1977;1:62-4.

2. Boltovskaia MN, Zaraǐskiı̌ EI, Fuks BB, Sukhikh GT, Kalafati TI, Starosvetskaia NA, Nazimova SV, marshitskaia MI, Likharev VA. Histochemical and clinical-diagnostic study of placental alpha 1microglobulin using monoclonal antibodies [In Russian]. Biull Eksp Biol Med 1991;112:397-400. [PubMed: 1725133]

3. Cousins LM, Smok DP, Lovett SM, Poeltler DM. AmniSure placental alpha microglobulin-1 rapid immunoassay versus standard diagnostic methods for detection of rupture of membranes. Am J Perinatol 2005;22:317-20. [PubMed: 16118720]

4. Lee SE, Park JS, Norwitz ER, Kim KW, Park HS, Jun JK. Measurement of placental alphamicroglobulin-1 in cervicovaginal discharge to diagnose rupture of membranes. Obstet Gynecol 2007;109:634-40. [PubMed: 17329514]

5. Friedman ML, McElin TW. Diagnosis of ruptured fetal membranes. Clinical study and review of the literature. Am J Obstet Gynecol 1969;104:544-50. [PubMed: 4182350]

6. de Haan HH, Offermans PM, Smits F, Schouten HJ, Peeters LL. Value of the fern test to confirm or reject the diagnosis of ruptured membranes is modest in nonlaboring women presenting with nonspecific vaginal fluid loss. Am J Perinatol Jan;1994 11(1):46-50. [PubMed: 8155212]

7. Lodeiro JG, Hsieh KA, Byers JH, Feinstein SJ. The fingerprint, a false-positive fern test. Obstet Gynecol 1989;73:873-4. [PubMed: 2704521]

8. McGregor JA, Johnson S. "Fig leaf" ferning and positive Nitrazine testing: semen as a cause of misdiagnosis of premature rupture of membranes. Am J Obstet Gynecol 1985;151:1142-3. [PubMed: 3985072]

9. Rosemond RL, Lombardi SJ, Boehm FH. Ferning of amniotic fluid contaminated with blood. Obstet Gynecol 1990;75:338-40. [PubMed: 2304705]

10. Kishida T, Yamada H, Negishi H, Sagawa T, Makinoda S, Fujimoto S. Diagnosis of premature rupture of the membranes in preterm patients, using an improved AFP kit: comparison with ROM-check and/ or nitrazine test. Eur J Obstet Gynecol Reprod Biol 1996;69:77-82. [PubMed: 8902437]

11. Erdemoglu E, Mungan T. Significance of detecting insulin-like growth factor binding protein-1 in cervicovaginal secretions: comparison with nitrazine test and amniotic fluid volume assessment. Acta Obstet Gynecol Scand 2004;83:622-6. [PubMed: 15225185]

12. Jeurgens-Borst AJ, Bekkers RL, Sporken JM, van den Berg PP. Use of insulin like growth factor binding protein-1 in the diagnosis of ruptured fetal membranes. Eur J Obstet Gynecol Reprod Biol 2002;102:11-4. [PubMed: 12039083]

13. Lockwood CJ, Senyei AE, Dische MR, Casal D, Shah KD, Thung SN, Jones L, Deligdisch L, Garite TJ. Fetal fibronectin in cervical and vaginal secretions as a predictor of preterm delivery. N Engl J Med 1991;325:669-74. [PubMed: 1870640]

14. Koninckx PR, Trappeniers H, Van Assche FA. Prolactin concentration in vaginal fluid: a new method for diagnosing ruptured membranes. Br J Obstet Gynaecol 1981;88:607-10. [PubMed: 7248218]

15. Buyukbayrak EE, Turan C, Unal O, Dansuk R, Cengizoglu B. Diagnostic power of the vaginal washing-fluid prolactin assay as an alternative method for the diagnosis of premature rupture of membranes. J Matern Fetal Neonatal Med 2004;15:120-5. [PubMed: 15209120]

16. Gross MM, Drobnic S, Keirse MJ. Influence of fixed and time-dependent factors on duration of normal first stage labor. Birth 2005;32:27-33. [PubMed: 15725202]

17. Mann SE, Lee JJ, Ross MG. Ovine intramembranous pathway permeability: use of solute clearance to determine membrane porosity. J Matern Fetal Med Oct;2001 10:335-40. [PubMed: 11730498]

18. Haddad R, Tromp G, Kuivaniemi H, Chaiworapongsa T, Kim YM, Mazor M, Romero R. Human spontaneous labor without histologic chorioamnionitis is characterized by an acute inflammation gene expression signature. Am J Obstet Gynecol 2006;195:394. e1-24. [PubMed: 16890549]

19. Seong HS, Lee SE, Kang JH, Romero R, Yoon BH. The frequency of microbial invasion of the amniotic cavity and histologic chorioamnionitis in women at term with intact membranes in the presence or absence of labor. Am J Obstet Gynecol 2008;199:375.e1-5. [PubMed: 18928978] 
20. Gotsch F, Romero R, Kusanovic JP, Erez O, Espinoza J, Kim CJ, Vaisbuch E, Than NG, MazakiTovi S, Chaiworapongsa T, et al. The anti-inflammatory limb of the immune response in preterm labor, intra-amniotic infection/inflammation, and spontaneous parturition at term: A role for interleukin-10. J Matern Fetal Neonatal Med 2008:21529-47. 


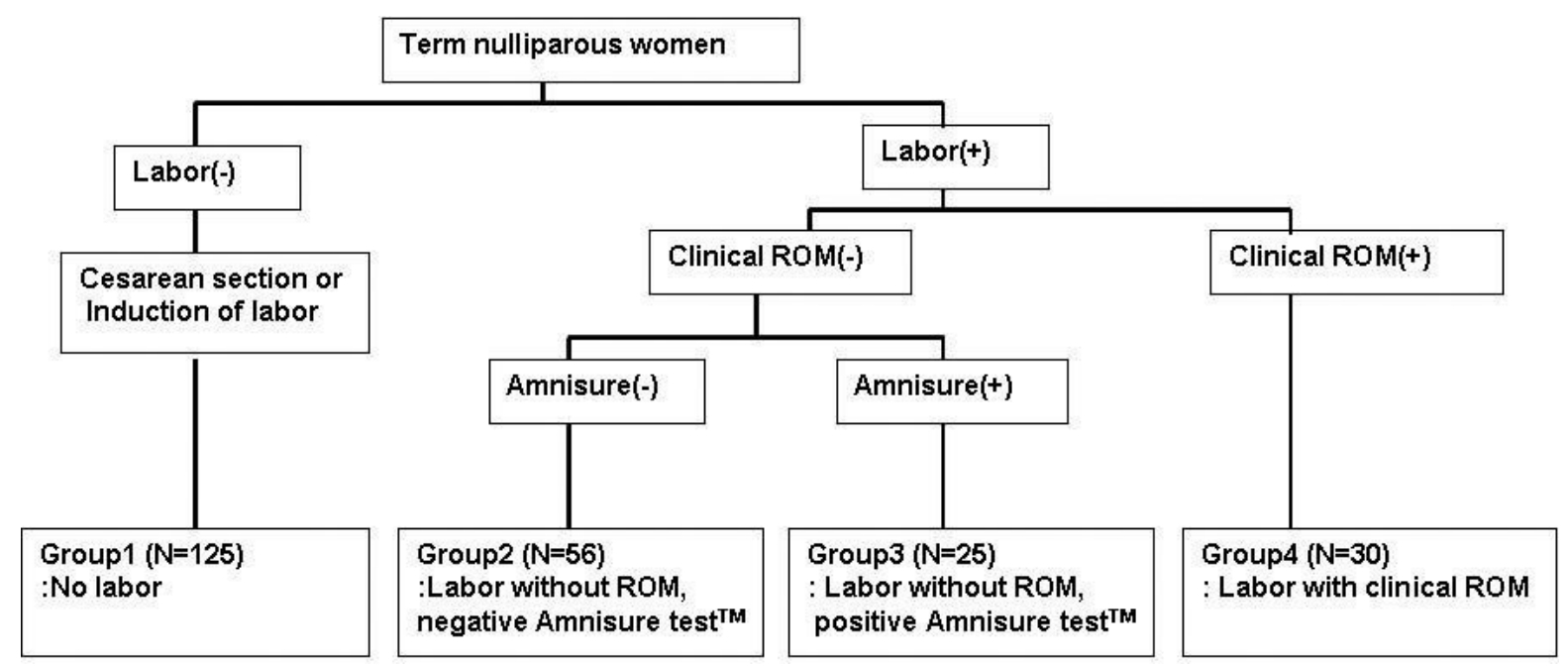

FIGURE 1.

Study population 


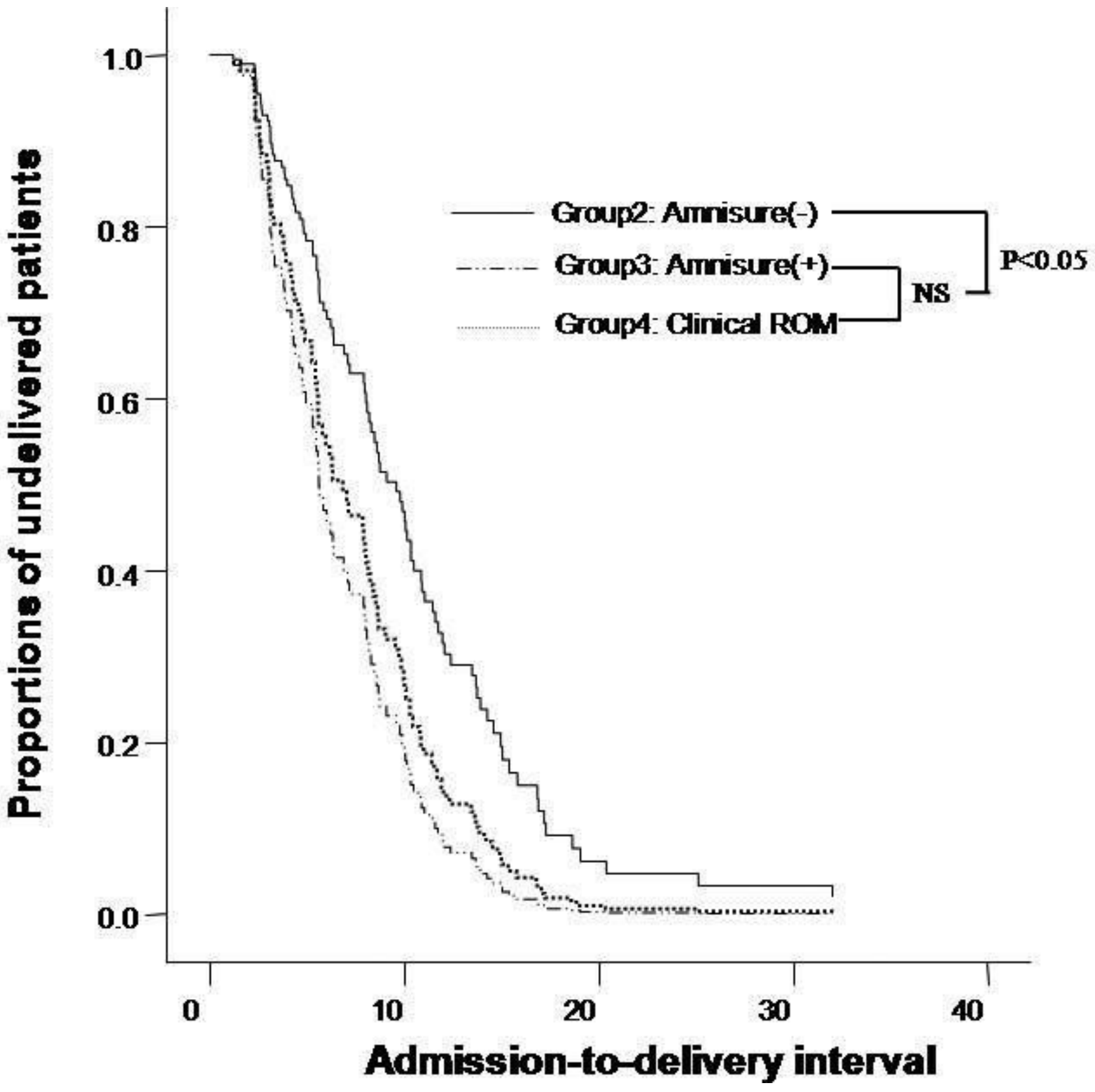

FIGURE 2.

Survival analysis of admission-to-delivery interval, according to the presence of clinical ROM and results of the Amnisure test ${ }^{\mathrm{TM}}$ (Group 2, in labor without clinical ROM with a negative Amnisure test ${ }^{\mathrm{TM}}$ : median, 9.79 hours [range, 2.32-33.07]; Group 3, in labor without clinical ROM with a positive Amnisure test ${ }^{\mathrm{TM}}$ : median, 6.88 hours [range, 1.18-15.98]; Group 4, in labor with clinical ROM: median, 5.58 hours [range, 1.80-33.47]). NS, Not significant 


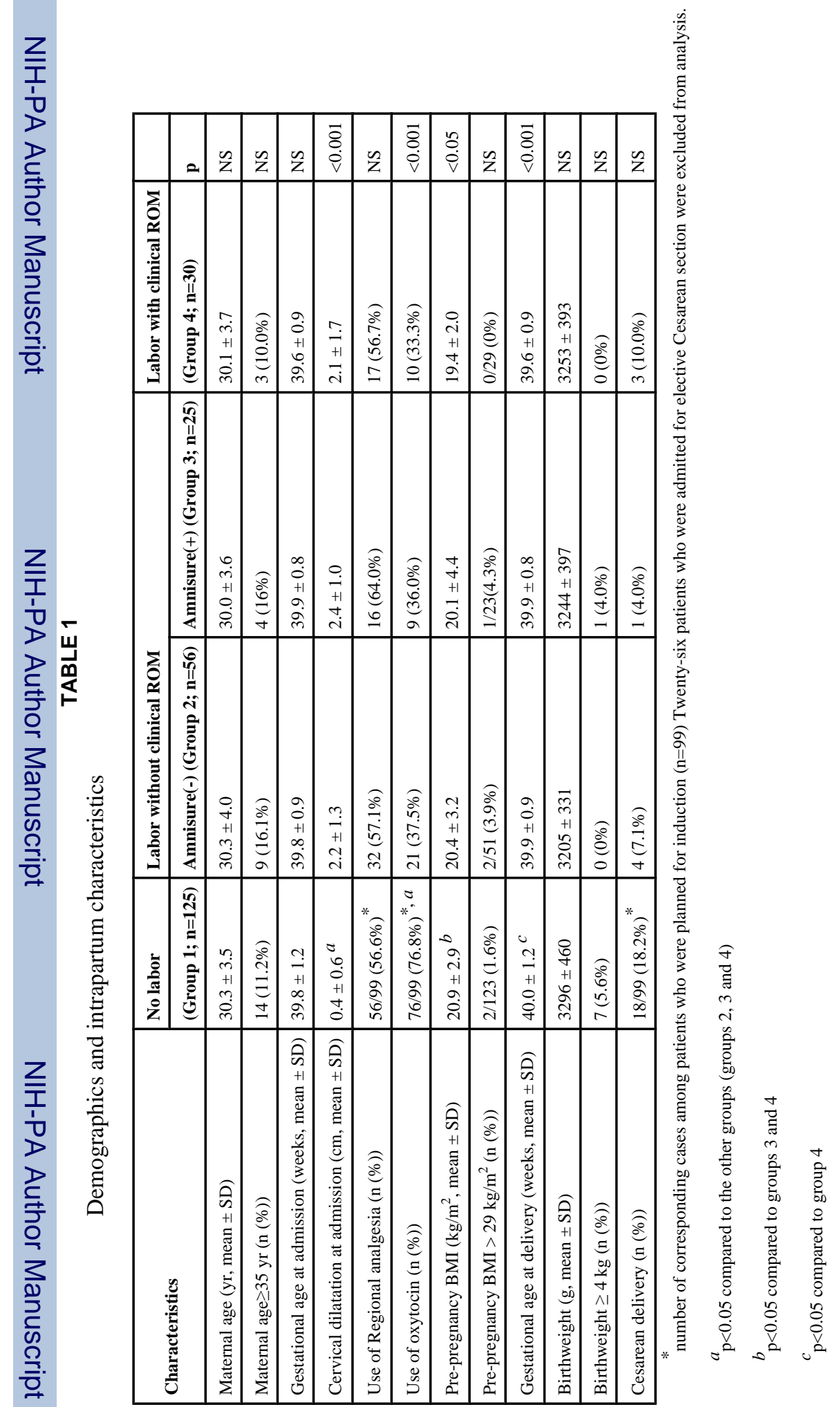

J Matern Fetal Neonatal Med. Author manuscript; available in PMC 2010 April 1. 